\title{
Usefulness of miRNA profiles for predicting pathological responses to neoadjuvant chemotherapy in patients with human epidermal growth factor receptor 2-positive breast cancer
}

\author{
HIDEYUKI OHZAWA $^{1}$, ATSUSHI MIKI ${ }^{2}$, TAKUMI TERATANI ${ }^{3}$, SATOMI SHIBA ${ }^{1}$, \\ YASUNARU SAKUMA ${ }^{2}$, WATARU NISHIMURA ${ }^{4}$, YASUKO NODA ${ }^{4}$, NORIYOSHI FUKUSHIMA ${ }^{5}$, \\ HIROFUMI FUJII ${ }^{6}$, YASUO HOZUMI ${ }^{1}$, HIROFUMI MUKAI ${ }^{7}$ and YOSHIKAZU YASUDA $^{2}$
}

\begin{abstract}
Departments of ${ }^{1}$ Breast Oncology and ${ }^{2}$ Gastrointestinal Surgery; ${ }^{3}$ Division of Development of Animal Resource, Center for Development of Advanced Medical Technology; ${ }^{4}$ Division of Bio-imaging and Neuro-cell Science, Department of Anatomy; Departments of ${ }^{5}$ Diagnostic Pathology and ${ }^{6}$ Clinical Oncology, Jichi Medical University, Shimotsuke, Tochigi 329-0498; ${ }^{7}$ Division of Breast and Medical Oncology,

National Cancer Center Hospital East, Kashiwa, Chiba 277-8577, Japan
\end{abstract}

Received May 29, 2015; Accepted December 20, 2016

DOI: $10.3892 / 01.2017 .5628$

\begin{abstract}
Pathological complete response (pCR) is considered to be a useful prognostic marker for neoadjuvant chemotherapy to improve the survival rate of patients with operable breast cancer. In the present study, we identified differentially expressed microRNAs (miRNAs) between pCR and non-pCR groups of patients with human epidermal growth factor receptor 2 (HER2)-positive breast cancer who received neoadjuvant chemotherapy with trastuzumab. Expression profiles were examined by miRNA microarrays using total RNA extracted from formalin-fixed, paraffin-embedded tissues from pretreatment biopsy specimens. Significant differences were observed in miRNAs associated with pCR between the luminal B-like (HER2-positive) and HER2-positive (nonluminal) subtypes, which were further classified according to their estrogen receptor (ER) status. Prediction models constructed with differentially expressed miRNAs performed well. In conclusion, the combination of miRNA profiles and ER status may improve the accuracy of $\mathrm{pCR}$ prediction in patients with HER2-positive breast cancer and enable the development of personalized treatment regimens.
\end{abstract}

\section{Introduction}

Human epidermal growth factor receptor 2 (HER2) is overexpressed in $\sim 20 \%$ of primary invasive breast cancer cases,

Correspondence to: Dr Yasuo Hozumi, Department of Breast Oncology, Jichi Medical University, 3311-1 Yakushiji, Shimotsuke, Tochigi 329-0498, Japan

E-mail: y-hozumi@jichi.ac.jp

Key words: microRNA, breast cancer, human epidermal growth factor receptor 2, neoadjuvant chemotherapy, pathological complete response while higher amplification has been correlated with more aggressive behavior and poorer clinical outcomes $(1,2)$. Trastuzumab, a monoclonal antibody that binds to the extracellular domain of HER2, is used as a targeted molecular therapy in combination with chemotherapy and has been demonstrated to improve the survival rate of patients with HER-2-positive metastatic breast cancer (3). Furthermore, the addition of trastuzumab to adjuvant chemotherapy has been demonstrated to improve disease-free survival (DFS) and overall survival (OS) of patients with HER2-positive operable breast cancer (4). Therefore, trastuzumab has become an significant therapeutic agent for patients with HER2-positive breast cancer.

The use of neoadjuvant chemotherapy is a recent treatment strategy for breast cancer that offers survival benefits equivalent to those of adjuvant chemotherapy and provides a means to predict prognosis $(5,6)$. Pathological complete response (pCR), which is characterized by the disappearance of invasive tumors in surgical specimens, is considered a useful prognostic marker, since patients who achieve pCR exhibit significant improvement in DFS and OS. Therefore, the identification of biomarkers to predict pathological responses may help to maximize the benefit of treatment and minimize the risk of adverse effects. The addition of trastuzumab to neoadjuvant chemotherapy for patients with HER2-positive breast cancer significantly improves the rate of $\mathrm{pCR}$ for these patients $(7,8)$; thus, it was recommended by the St. Gallen International Expert Consensus on the Primary Therapy of Early Breast Cancer in 2013 (9).

HER2-positive breast cancer is divided into two subtypes according to estrogen receptor (ER) status using immunohistochemical analysis as a surrogate for the classification of intrinsic subtypes by molecular assays, while ER-positive tumors are classified as either 'HER2-positive (nonluminal)' or 'luminal B-like (HER2-positive)' subtypes, respectively (9). However, there exists a discrepancy in the pathological responses and survival benefits of neoadjuvant chemotherapy between these two HER2-positive subtypes (10). Therefore, 
new predictive markers in combination with conventional markers, including immunohistochemical ER and HER2 status, are required.

MicroRNAs (miRNAs) are short noncoding RNAs, ranging in length from 20 to 25 nucleotides, which regulate protein synthesis at the post-transcriptional level by binding to the 3' untranslated region of mRNAs (11). Numerous miRNAs are reported to be related to dysregulation and various cancers. For example, miR-21, which is a well-studied oncomiR, was reported to be associated with HER2-positive breast cancer. Higher expression of miR-21 is associated with positive HER2 status, and miR-21 inhibits apoptosis through targeting tumor suppressors including phosphatase and tensin homolog (12). miRNAs play essential roles in breast cancer pathogenesis through a complex gene regulation network, and several have been implicated in resistance and sensitivity to breast cancer therapeutic drugs (13). miRNAs are well-preserved in a range of specimen types, including plasma, urine and formalin-fixed paraffin-embedded (FFPE) tissues (13). Since miRNA expression profiles differ among breast cancer subtypes, as determined by gene expression profiles and immunohistochemical findings $(14,15)$, we speculated that miRNAs may be efficient predictive markers of the response of neoadjuvant chemotherapy.

In the present study, we evaluated the use of differentially expressed miRNA profiles of biopsy specimens collected prior to neoadjuvant chemotherapy with trastuzumab for patients with HER2-positive breast cancer between pCR and non-pCR patient groups to predict the pathological response of neoadjuvant chemotherapy. To the best of our knowledge, few studies have investigated miRNA profiles associated with the pathological response of neoadjuvant chemotherapy for patients with HER2-positive breast cancer according to ER status. The aim of this study was to develop a more reliable prediction of neoadjuvant chemotherapy outcomes using differentially expressed miRNA profiles in combination with ER and HER2 status.

\section{Materials and methods}

Patient population. The study protocol was approved by the Bioethics Committee for Human Genome and Gene Analysis of Jichi Medical University, Tochigi, Japan (approval no. 13-10), and written informed consent was obtained from all participants. We retrospectively reviewed the medical records of 47 consecutive patients with HER2-positive breast cancer who received neoadjuvant chemotherapy with trastuzumab at the Department of Breast Surgery, Jichi Medical University Hospital, between January 2006 and December 2011. All patients had pathologically confirmed HER2-positive invasive breast cancer by ultrasound-guided core needle biopsies prior to treatment. FFPE blocks of pretreatment biopsy specimens were available for 40 cases $(85.1 \%)$. The remaining seven cases were excluded from this study as the biopsies were performed in other institutions.

Treatment. Neoadjuvant chemotherapy consisted of anthracycline-based regimens, followed by taxane-based regimens. The following three anthracycline-based regimens were used: three or four cycles of FEC (fluorouracil $500 \mathrm{mg} / \mathrm{m}^{2}$, epirubicin $100 \mathrm{mg} / \mathrm{m}^{2}$, and cyclophosphamide $500 \mathrm{mg} / \mathrm{m}^{2}$
Table I. Summary of yield and quality of extracted RNA samples.

\begin{tabular}{lrc}
\hline Variables & Median & Range \\
\hline Concentration $(\mathrm{ng} / \mu \mathrm{l})$ & 102.10 & 24.40 to 374.50 \\
A260/280 & 1.96 & 1.70 to 2.06 \\
A260/230 & 1.74 & 1.00 to 1.95 \\
RNA integrity number & 2.40 & 1.70 to 2.50 \\
\hline
\end{tabular}

A260/280, ratio of absorbance at 260 and $280 \mathrm{~nm}$. A260/230, ratio of absorbance at 260 and $230 \mathrm{~nm}$.

every 3 weeks); four cycles of AC (adriamycin $60 \mathrm{mg} / \mathrm{m}^{2}$ and cyclophosphamide $600 \mathrm{mg} / \mathrm{m}^{2}$ every 3 weeks); and four cycles of EC (epirubicin $90 \mathrm{mg} / \mathrm{m}^{2}$ and cyclophosphamide $600 \mathrm{mg} / \mathrm{m}^{2}$ every 3 weeks). The three taxane-based regimens were as follows: three or four cycles of docetaxel $\left(100 \mathrm{mg} / \mathrm{m}^{2}\right.$ every 3 weeks); four cycles of docetaxel $\left(75 \mathrm{mg} / \mathrm{m}^{2}\right.$ every 3 weeks); and 12 cycles of paclitaxel $\left(80 \mathrm{mg} / \mathrm{m}^{2}\right.$ every weeks). All patients received trastuzumab regimens $(4 \mathrm{mg} / \mathrm{kg}$ as a loading dose and $2 \mathrm{mg} / \mathrm{kg}$ from the second dose onward every week) concomitantly with a taxane-based regimen. Surgery was performed 3-4 weeks after the final dose of the neoadjuvant chemotherapy regimen.

Pathological evaluation. Expression levels of ER (SP1; Roche Diagnostics Deutschland GmbH, Mannheim, Germany), progesterone receptor (PR; 1E2; Roche Diagnostics) and HER2 (4B5; Roche Diagnostics) in the biopsy specimens were routinely subjected to immunohistochemical analysis. The cut-off value for ER and PR positivity was $\geq 10 \%$ positive cells. HER 2 expression was scored on a scale of 0-3+, in accordance with the American Society of Clinical Oncology/College of American Pathologists guidelines (16). A score of 0-1+ was considered negative, while a score of $3+$ was considered positive. For 2+ cases, HER 2 amplification was verified by fluorescence in situ hybridization using a PathVysion HER-2 DNA Probe kit (Abbott/Vysis, Des Plaines, IL, USA). Tumors were categorized into two subtypes on the basis of ER and HER2 status of the biopsy specimens as surrogate markers: the luminal B-like (HER2-positive) subtype (ER- and/or PR-positive, HER2-positive) and the HER2-positive (nonluminal) subtype (ER- and PR-negative, HER2-positive). Following surgery, residual tumors in the resected specimens were pathologically evaluated. The pathological responses of neoadjuvant chemotherapy were determined according to the status of residual invasive tumors. A pCR was defined as no pathological evidence of residual invasive cancer in breast and axillary lymph nodes, irrespective of the remaining intraductal components.

Isolation of total RNA. Four serial $10-\mu$ m-thick sections of FFPE tissue specimens were mounted onto Leica PEN-membrane slides (Leica Mikrosysteme Vertrieb GmbH, Wetzlar, Germany) and stained with cresyl violet (Ambion Life Technologies, Austin, TX, USA). Neoplastic portions of each specimen were collected by laser capture microdissection using a laser microdissection (LMD) system (LMD7000; 

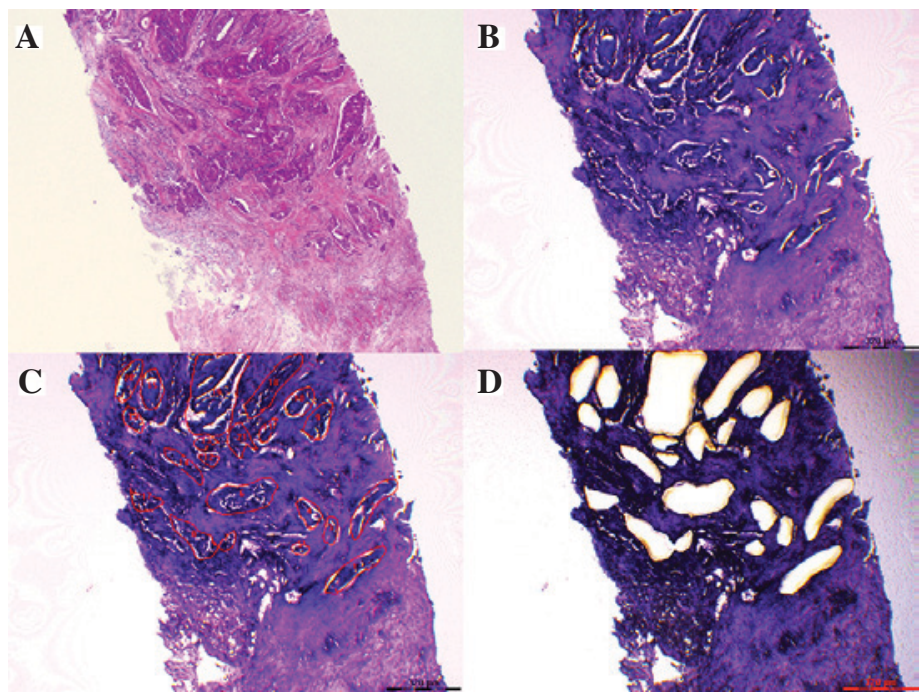

Figure 1. Example of laser capture microdissection. (A) FFPE section (4 $\mu \mathrm{m})$ was stained with hematoxylin-eosin. (B) FFPE section (10 $\mu \mathrm{m})$ was stained with cresyl violet on a PEN-membrane slide. (C) Neoplastic portions of specimen were defined before cutting (red lines). (D) Specimen was cut along the definition. Dissectates were collected by gravity. FFPE, formulin-fixed paraffin-embedded.

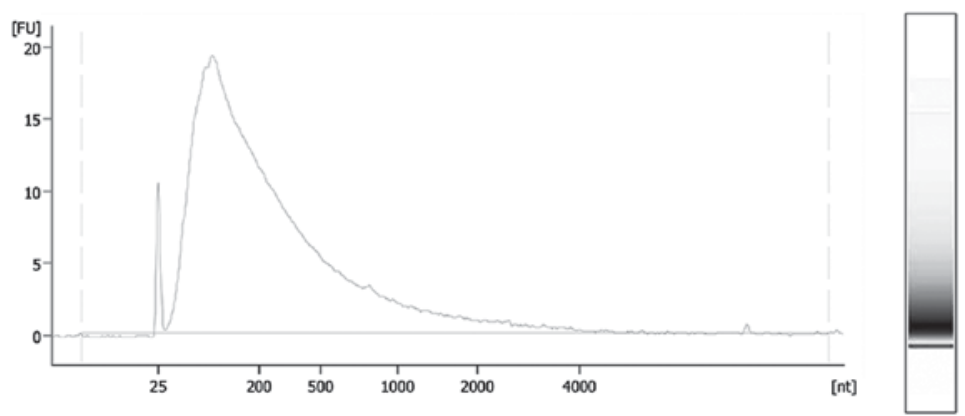

Figure 2. Example of electrophoretic RNA measurement recorded with an Agilent 2100 bioanalyzer. The electropherogram represents the size of distribution in nt and FU. Peak of RNA fragments was located at $100 \mathrm{nt}$ in length.RNA integrity number of this sample was 2.3 . FU, fluorescence units.

Leica Mikrosysteme Vertrieb GmbH; Fig. 1). RNA extraction was performed using an miRNeasy FFPE kit (Qiagen, Hilden, Germany) according to the manufacturer's instructions. Total RNA in the samples was quantified using a Qubit RNA HS Assay kit and Qubit 2.0 fluorometer (Life Technologies, Palo Alto, CA, USA), while RNA quality was assessed using a NanoDrop 1000 spectrophotometer (Thermo Fisher Scientific, Inc., Wilmington, DE, USA) and Agilent 2100 Bioanalyzer (Agilent Technologies, Inc., Santa Clara, CA, USA; Fig. 2). Total RNA was extracted from FFPE sections of pretreatment biopsy specimens from all 40 patients. The yield and quality of all samples were checked prior to subsequent analyses (Table I). The median concentration of extracted RNA was $102.1 \mathrm{ng} / \mu \mathrm{l}$ (range, 24.4-374.5 ng/ $\mu \mathrm{l}$ ). The median 260/280 and 260/230 nm ratios of absorbance were 1.96 (range, 1.70-2.06) and 1.74 (range, 1.00-1.95), respectively. The median RNA integrity number, which indicates the degree of RNA degradation, was 2.4 (range, 1.7-2.5).

miRNA microarray expression analysis. Total RNA (100 ng) was labeled with cyanine 3-pCp using the Agilent miRNA Complete Labeling and Hyb kit (Agilent Technologies, Inc.). Labeled RNA was hybridized to an Agilent SurePrint G3 Human miRNA microarray $(8 \times 60 \mathrm{~K}$, release 19.0; Agilent
Technologies, Inc.) for $20 \mathrm{~h}$ at $55^{\circ} \mathrm{C}$ in a hybridization chamber. Following hybridization, the array was washed and scanned with an Agilent G2505C microarray scanner (Agilent Technologies, Inc.) at $3 \mu \mathrm{m}$ resolution. miRNA expression data were extracted from the scanned images with Feature Extraction software (version 10.7.3.1; Agilent Technologies, Inc.).

Data processing and statistical analysis. miRNA expression data were analyzed using GeneSpring software (version 13.0; Agilent Technologies, Inc.) and normalized using a 90th percentile normalization algorithm, followed by preprocessing baseline to median data of all samples. miRNAs were filtered based on signal intensity values with a lower percentile cut-off value of $20 \%$ in more than $50 \%$ of the samples in any one category. Unsupervised hierarchical cluster analysis was performed on filtered data. Expression differences between objective groups were determined using a moderated t-test. Differences of more than two-fold with a probability P-value $<0.05$ were considered statistically significant. Prediction models for pathological responses were developed using a partial least squares discrimination (PLSD) model with GeneSpring software, and a prediction model for non-pCR was based on expression values of differentially expressed miRNAs. Prediction results are presented as $t$-scores computed with Prism 5 statistical software 
Table II. Patient characteristics.

\begin{tabular}{|c|c|c|c|c|}
\hline Characteristics & All patients & $\begin{array}{l}\text { Luminal B-like } \\
\text { (HER2-positive) }\end{array}$ & $\begin{array}{l}\text { HER2-positive } \\
\text { (nonluminal) }\end{array}$ & P-value \\
\hline Number of patients & 40 & 17 & 23 & \\
\hline Median age (range) & $55(31-83)$ & $49(33-66)$ & $58(31-83)$ & 0.01 \\
\hline Median tumor size (range, $\mathrm{cm}$ ) & $3.4(1.2-6.8)$ & $3.1(1.3-6.8)$ & $3.5(1.2-6)$ & 0.78 \\
\hline Clinical axillary node status & & & & 0.37 \\
\hline Metastasis & $34(85.0 \%)$ & $13(76.5 \%)$ & $21(91.3 \%)$ & \\
\hline No metastasis & $6(15.0 \%)$ & $4(23.5 \%)$ & $2(8.7 \%)$ & \\
\hline Clinical stage & & & & 0.31 \\
\hline 2 & $26(65.0 \%)$ & $13(76.5 \%)$ & $13(56.5 \%)$ & \\
\hline 3 & $14(35.0 \%)$ & $4(23.5 \%)$ & $10(43.5 \%)$ & \\
\hline Regimen of neoadjuvant chemotherapy & & & & 0.49 \\
\hline Anthracycline followed by taxane & $38(95.0 \%)$ & $17(100 \%)$ & $21(91.3 \%)$ & \\
\hline Taxane-based (without anthracycline) & $2(5.0 \%)$ & $0(0 \%)$ & $2(8.7 \%)$ & \\
\hline Pathological response & & & & 0.04 \\
\hline $\mathrm{pCR}$ & $15(37.5 \%)$ & $3(17.6 \%)$ & $12(52.2 \%)$ & \\
\hline Non-pCR & $25(62.5 \%)$ & $14(82.3 \%)$ & $11(47.8 \%)$ & \\
\hline
\end{tabular}

HER2, human epidermal growth factor receptor 2; pCR, pathological complete response.

(version 5.0f; GraphPad Software, Inc., La Jolla, CA, USA). The $t$-scores were plotted and compared between the pCR and non-pCR groups using the Mann-Whitney U-test. Receiver operating characteristic (ROC) curves were drawn and the area under the ROC curve (AUC) was calculated. Patient characteristics were compared between the HER2-positive (nonluminal) and luminal B-like (HER2-positive) subtypes using Prism 5 software. Fisher's exact test was used to compare categorical data. The Mann-Whitney U-test was used to compare continuous data.

\section{Results}

Patient characteristics. Medical records from a total of 40 females with stage II or III breast cancer were included for analysis (Table II). The median age at diagnosis was 55 years (range, 31-83 years). A total of 17 and 23 patients, respectively, were diagnosed as the luminal B-like (HER2-positive) or HER2-positive (nonluminal) subtype. Patients with HER2-enriched tumors (ER-negative) were older than those with luminal-HER2 hybrid tumors (ER-positive) $(\mathrm{P}=0.01)$. There were no significant differences in median tumor size, clinical axillary node status, clinical stage or neoadjuvant chemotherapy regimen between subtypes $(\mathrm{P}=0.78,0.37$, 0.31 and 0.49 , respectively). The pCR of the HER2-positive (nonluminal) subtype was significantly greater than that of the luminal B-like (HER2-positive) subtype $(\mathrm{P}=0.04)$.

miRNA expression profiles associated with pathological response of neoadjuvant chemotherapy. Unsupervised hierarchical clustering using the full dataset of 2,024 miRNA expression profiles of all 40 patients was insufficient to differentiate between the pCR and non-pCR groups (Fig. 3A). Unsupervised cluster analyses were also performed following categorization into HER2-positive (nonluminal; Fig. 3B) and luminal B-like (HER2-positive) subtypes (Fig. 3C); however, these were also insufficient to predict the pCR group.

Twenty-one miRNAs were differentially expressed between the non-pCR and pCR groups in the analysis of all 40 patients with HER2-positive breast cancer (Table III). Nine of these 21 miRNAs are reported to be associated with breast cancer (17-25). The other 12 miRNAs have no reported correlation with breast cancer. Furthermore, differential miRNA expression was separately examined according to the luminal B-like (HER2-positive) and HER2-positive (nonluminal) subtypes. For the luminal B-like (HER2-positive) subtype, 17 miRNAs were differentially expressed (Table IV), and nine of these 17 miRNAs are reported to be correlated with breast cancer (20-22,24,26-30). For the HER2-positive (nonluminal) subtype, 14 miRNAs were differentially expressed (Table V), and five of these are reported to be correlated with breast cancer $(17,23,25,31,32)$. The miRNA expression profiles associated with pathological response differed completely between the HER2-positive (nonluminal) and luminal B-like (HER2-positive) subtypes.

Generation of a prediction model for pathological response to neoadjuvant chemotherapy of HER2-positive breast cancer. After evaluating differential miRNA expression, a prediction model for pathological response was constructed using the 21 differentially expressed miRNAs identified by analysis of all 40 patients. The distribution of t-scores significantly differed between the pCR and non-pCR groups $(\mathrm{P}<0.001$; Fig. 4A). Performance of the prediction model was evaluated using discriminant analysis with ROC curves. The AUC was 0.8827 , indicating moderate accuracy of this model in predicting pathological responses. We further examined the results of this prediction model separately for the HER2-positive 
A

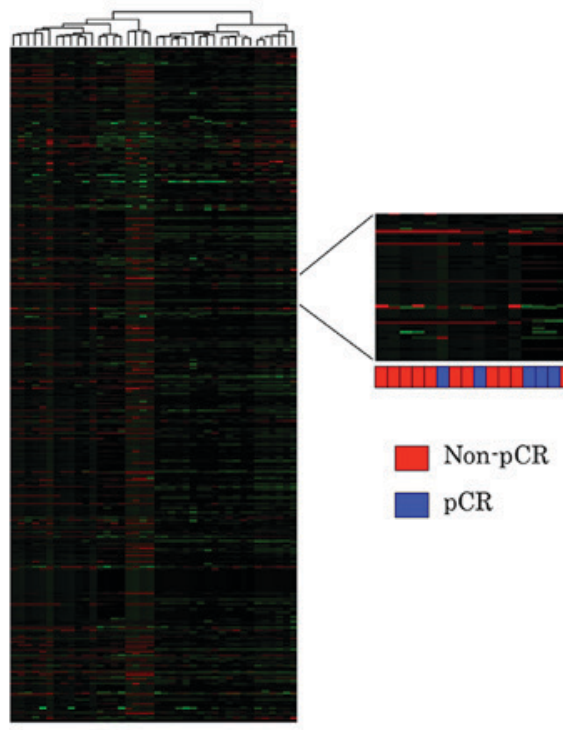

B

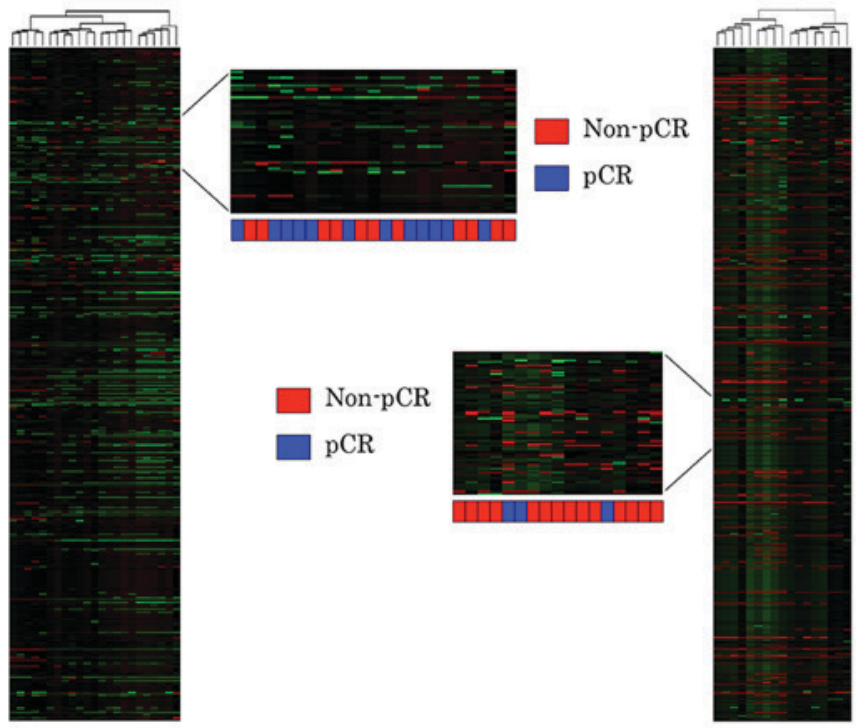

Figure 3. (A) Unsupervised hierarchical cluster analysis using the full dataset of 2,024 miRNA expression profiles of all 40 patients. (B) Unsupervised hierarchical cluster analysis using the full dataset of 2,024 miRNA expression profiles of patients with HER2-positive (nonluminal) breast cancer. (C) Unsupervised hierarchical cluster analysis using the full dataset of 2,024 miRNA expression profiles of patients with luminal B-like (HER2-positive) breast cancer. The insets show details from the main heat map. The categorical variables were pCR and non-pCR, listed below the insets. HER2, human epidermal growth factor receptor 2; pCR, pathological complete response.

(nonluminal) and luminal B-like (HER2-positive) subtypes. There were significant differences in the distribution of t-scores $(\mathrm{P}<0.001)$ between the $\mathrm{pCR}$ and non-pCR groups in the HER2-positive (nonluminal) subtype (Fig. 4B), whereas no significant difference was observed for the luminal B-like (HER2-positive) subtype ( $\mathrm{P}=0.051$; Fig. 4C). In discriminant analyses with the ROC curve, the AUCs were 0.9242 for the HER2-positive (nonluminal) subtype and 0.8810 for the luminal B-like (HER2-positive) subtype, respectively (Fig. 4B and C). These results demonstrate that the predictive ability for the HER2-positive (nonluminal) subtype
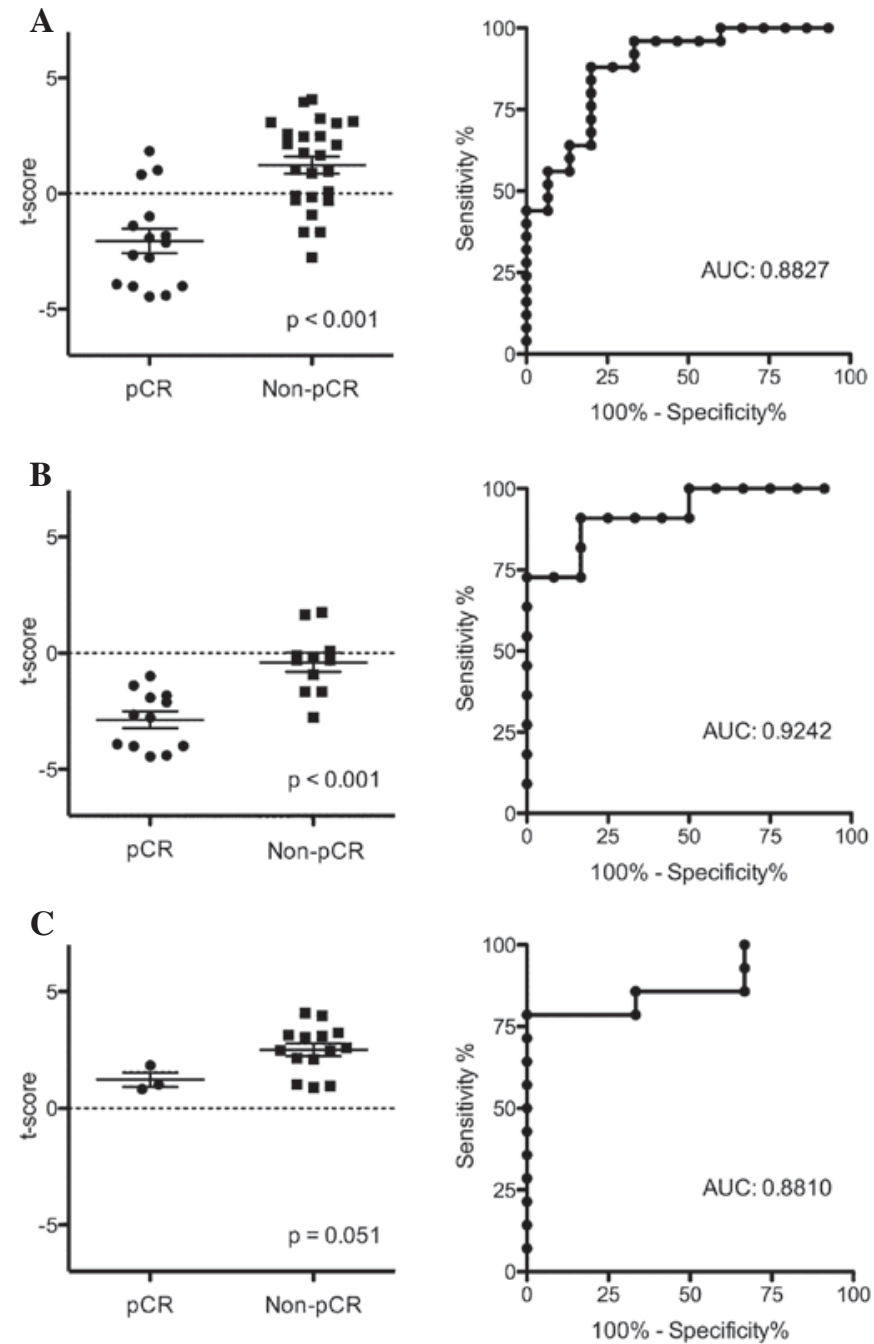

Figure 4. (A) Distribution of t-scores and ROC curve to predict the pCR of all 40 patients. (B) Distribution of t-scores and ROC curve to predict the $\mathrm{pCR}$ of patients with HER2-positive (nonluminal) breast cancer. (C) Distribution of t-scores and ROC curve to predict the pCR of patients with luminal B-like (HER2-positive) breast cancer. The t-scores were computed using differentially expressed miRNAs between the pCR and non-pCR groups. ROC, receiver operating characteristics; $\mathrm{pCR}$, pathological complete response; AUC, area under the ROC curve; HER2, human epidermal growth factor receptor 2 .

is better than that for the luminal B-like (HER2-positive) subtype. A prediction model of pathological response was also constructed using the 14 miRNAs differentially expressed in the HER2-positive (nonluminal) subtype. The distribution of $\mathrm{t}$-scores significantly differed $(\mathrm{P}<0.001)$ between the $\mathrm{pCR}$ and non-pCR groups, and the AUC was 0.9621 (Fig. 5). These results indicate that the prediction model for the HER2-positive (nonluminal) subtype was more suitable than that of the prediction model using 21 differentially expressed miRNAs in the analysis of all 40 patients. A model for the luminal B-like (HER2-positive) subtype could not be constructed as the data were not suitable for classification using the PLSD algorithm.

\section{Discussion}

In the present study, we identified miRNA expression profiles of biopsy specimens from patients with HER2-positive 
Table III. Differential miRNA expression between non-pCR and pCR in all 40 patients.

\begin{tabular}{|c|c|c|c|c|}
\hline miRNA & P-value & Fold change & Regulation & Function correlated with breast cancer \\
\hline $\operatorname{miR}-106 b-3 p$ & 0.046 & 2.97 & Down & $\begin{array}{l}\text { Downregulated in bone metastasis patients with } \\
\text { breast cancer (17) }\end{array}$ \\
\hline $\operatorname{miR}-1180$ & 0.035 & 4.64 & Down & $\mathrm{N} / \mathrm{A}$ \\
\hline $\operatorname{miR}-1238-5 p$ & 0.046 & 3.00 & Down & $\mathrm{N} / \mathrm{A}$ \\
\hline $\operatorname{miR}-142-5 p$ & 0.035 & 2.73 & Down & Upregulated in human breast cancer stem cells (18) \\
\hline $\operatorname{miR}-150-5 p$ & 0.030 & 2.05 & Down & $\begin{array}{l}\text { Overexpression promotes growth and reduces apotosis in } \\
\text { breast cancer cells (19) }\end{array}$ \\
\hline $\operatorname{miR}-181 c-5 p$ & 0.016 & 4.27 & Down & $\begin{array}{l}\text { Predictive miRNA corresponding with HER2 status in } \\
\text { early-stage breast cancer (20) }\end{array}$ \\
\hline miR-182-5p & 0.021 & 3.18 & Down & $\mathrm{N} / \mathrm{A}$ \\
\hline $\operatorname{miR}-200 a-5 p$ & 0.028 & 4.85 & Down & $\begin{array}{l}\text { Higher level of circulating miR-200a in CTC-positive MBC } \\
\text { patients (21) }\end{array}$ \\
\hline miR-210 & 0.046 & 2.22 & Up & $\begin{array}{l}\text { Higher expression correlates with poor prognosis of patients } \\
\text { with breast cancer ( } 22)\end{array}$ \\
\hline miR-218-5p & 0.013 & 5.99 & Down & $\begin{array}{l}\text { Downregulated in cisplatin-resistant breast cancer } \\
\text { cell lines }(23)\end{array}$ \\
\hline miR-31-3p & 0.043 & 2.04 & Up & Upregulated in chemoresistant breast cancer tissues (24) \\
\hline $\operatorname{miR}-3609$ & 0.026 & 3.84 & Down & $\mathrm{N} / \mathrm{A}$ \\
\hline $\operatorname{miR}-362-5 p$ & 0.049 & 3.33 & Down & $\mathrm{N} / \mathrm{A}$ \\
\hline $\operatorname{miR}-3620-3 p$ & 0.046 & 3.72 & Down & $\mathrm{N} / \mathrm{A}$ \\
\hline $\operatorname{miR}-4418$ & 0.030 & 4.40 & Down & $\mathrm{N} / \mathrm{A}$ \\
\hline $\operatorname{miR}-449 \mathrm{a}$ & 0.028 & 6.44 & Up & N/A \\
\hline miR-449b-5p & 0.037 & 3.15 & Up & N/A \\
\hline miR-4506 & 0.015 & 4.95 & Down & $\mathrm{N} / \mathrm{A}$ \\
\hline miR-4657 & 0.049 & 3.37 & Down & $\mathrm{N} / \mathrm{A}$ \\
\hline miR-505-3p & 0.026 & 3.44 & Down & $\begin{array}{l}\text { Tumor suppressive miRNA, which correlates inversely with } \\
\text { drug sensitivity (25) }\end{array}$ \\
\hline miR-505-5p & 0.012 & 3.75 & Down & \\
\hline
\end{tabular}

pCR, pathological complete response; N/A, not applicable; CTC, circulating tumor cell; MBC, metastatic breast cancer.
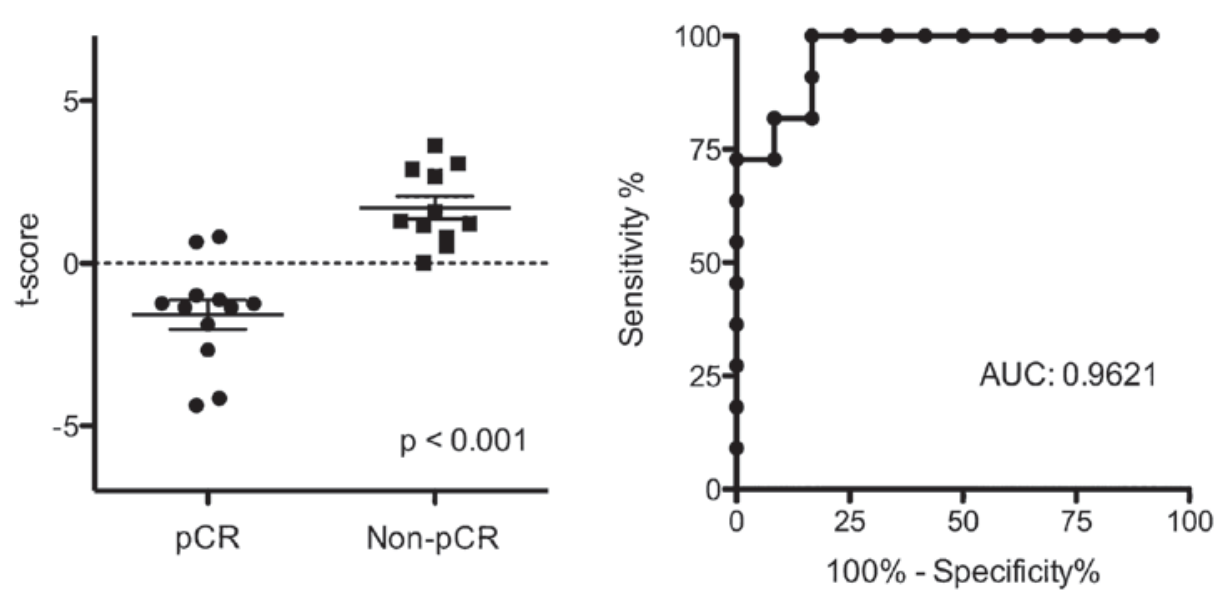

Figure 5. Distribution of t-scores and receiver operating characteristics curve to predict $\mathrm{pCR}$ using a prediction model constructed from the 14 miRNAs differentially expressed between the $\mathrm{pCR}$ and non-pCR groups of the human epidermal growth factor receptor 2-positive (nonluminal) subtype. pCR, pathological complete response; AUC, area under the ROC curve.

breast cancer prior to neoadjuvant chemotherapy with trastuzumab. The miRNAs associated with pathological response significantly differed between the HER2-positive (nonluminal) and luminal B-like (HER2-positive) subtypes. The prediction 
Table IV. Differential miRNA expression between non-pCR and pCR in luminal B-like (HER2-positive) subtype.

\begin{tabular}{|c|c|c|c|c|}
\hline miRNA & P-value & Fold change & Regulation & Function correlated with breast cancer \\
\hline $\operatorname{miR}-148 b-3 p$ & 0.041 & 5.035 & Up & $\begin{array}{l}\text { Higher level of circulating miR-148b in breast cancer } \\
\text { patients (26) }\end{array}$ \\
\hline $\operatorname{miR}-151 a-3 p$ & 0.043 & 4.635 & Up & $\mathrm{N} / \mathrm{A}$ \\
\hline miR-152 & 0.016 & 4.490 & Up & $\begin{array}{l}\text { Upregulation indirectly interacts with MAPK signaling } \\
\text { pathway (27) }\end{array}$ \\
\hline miR-203a & 0.027 & 18.271 & Up & $\begin{array}{l}\text { Higher level of circulating miR-203 in CTC-positive MBC } \\
\text { patients }(21)\end{array}$ \\
\hline miR-210 & 0.022 & 10.120 & Up & $\begin{array}{l}\text { Higher expression correlates with poor prognosis of patients } \\
\text { with breast cancer (22) }\end{array}$ \\
\hline miR-28-5p & 0.039 & 4.214 & Up & N/A \\
\hline $\operatorname{miR}-301 b$ & 0.007 & 3.485 & Down & $\begin{array}{l}\text { Oncogenic miRNA, miR-301 attenuation decreases cell } \\
\text { proliferation and invasion (28) }\end{array}$ \\
\hline miR-34b-5p & 0.037 & 4.754 & Up & $\begin{array}{l}\text { miR-34 and p53 regulate epithelial-mesenchymal transition of } \\
\text { cancer cells ( } 29)\end{array}$ \\
\hline $\operatorname{miR}-376 c-3 p$ & 0.019 & 21.261 & Up & Upregulated in plasma of patients with breast cancer (30) \\
\hline $\operatorname{miR}-377-3 p$ & 0.039 & 11.814 & Up & $\begin{array}{l}\text { Predictive miRNA corresponding with PR status in early-stage } \\
\text { breast cancer (20) }\end{array}$ \\
\hline $\operatorname{miR}-3907$ & 0.006 & 4.389 & Up & $\mathrm{N} / \mathrm{A}$ \\
\hline $\operatorname{miR}-429$ & 0.037 & 7.079 & $\mathrm{Up}$ & Overexpressed in chemoresistant breast cancer cells (24) \\
\hline $\operatorname{miR}-4291$ & 0.006 & 5.189 & $\mathrm{Up}$ & $\mathrm{N} / \mathrm{A}$ \\
\hline $\operatorname{miR}-4737$ & 0.007 & 4.726 & Down & $\mathrm{N} / \mathrm{A}$ \\
\hline $\operatorname{miR}-487 b$ & 0.040 & 9.634 & Up & N/A \\
\hline $\operatorname{miR}-5684$ & 0.036 & 4.578 & Up & $\mathrm{N} / \mathrm{A}$ \\
\hline $\operatorname{miR}-582-5 p$ & 0.007 & 4.721 & Down & N/A \\
\hline
\end{tabular}

pCR, pathological complete response; HER2, human epidermal growth factor receptor 2; N/A, not applicable; MAPK, mitogen-activated protein kinase; CTC, circulating tumor cell; MBC, metastatic breast cancer; PR, progesterone receptor.

models of pathological responses constructed using miRNAs differentially expressed between the pCR and non-pCR groups demonstrated considerable reliability.

Breast cancer may be classified into subtypes according to gene expression profiles (33). Surrogate subtype classification obtained by immunohistochemical analyses of ER, PR, Ki-67 and HER2 is often used in clinical practice (9). In previous studies, miRNA expression profiles differed according to the breast cancer subtype $(14,15)$. However, several previous studies of miRNA expression profiles of neoadjuvant chemotherapy for patients with HER2-positive breast cancer did not classify patients according to hormone receptor status $(34,35)$. The pathological response and survival benefit of neoadjuvant chemotherapy with trastuzumab reportedly differs between two HER2-positive subtypes divided by hormone receptor status (10). Therefore, we classified HER2-positive breast cancer into subtypes based on ER status and subsequently analyzed miRNA expression. The results of our study revealed significant differences in the miRNA profiles associated with pathological responses between the HER2-positive (nonluminal) and luminal B-like (HER2-positive) subtypes. We further constructed models to predict pathological responses using differentially expressed miRNAs. The combination of breast cancer subtypes and miRNA expression profiles offers a means to accurately and efficiently predict pathological responses.
We identified a total of 52 differentially expressed miRNAs in the analysis of all 40 patients: 21 according to pCR status (Table III), 17 by analysis of the luminal B-like (HER2-positive) subtype (Table IV), and 14 by analysis of the HER2-positive (nonluminal) subtype (Table V), respectively. A total of 48 miRNAs were selected due to the overlap of four miRNAs (i.e., miR-210, miR-106b, miR-505 and miR-218). miR-210 was upregulated in the analyses of all 40 patients and the luminal B-like (HER2-positive) subtype. Correlations between increased miR-210 expression and poor prognosis in various cancers, particularly in breast cancer, as well as associations with the hypoxic pathway in a hypoxia-inducible factor-dependent manner have been reported elsewhere $(22,36)$. miR-106b-3p, miR-218-5p and miR-505-5p were downregulated in the analyses of all 40 patients and the HER2-positive (nonluminal) subtype. Downregulation of miR-106b involves bone metastasis of breast cancer with negative regulation of matrix metalloproteinase 2 (17). miR-218 was downregulated in cisplatin-resistant breast cancer cell lines and regulated chemosensitivity by targeting BRCA1 (23). miR-505 has been reported as a tumor-suppressive miRNA, and is inversely correlated with Akt3, which modulates drug sensitivity (25). The remaining differentially expressed 15 miRNAs between the non-pCR and pCR groups are reportedly involved in the progression of breast cancer (Tables III-V). To the best of our 
Table V. Differential miRNA expression between non-pCR and pCR in HER2-positive (nonluminal) subtype.

\begin{tabular}{|c|c|c|c|c|}
\hline miRNA & P-value & Fold change & Regulation & Function correlated with breast cancer \\
\hline let-7a-3p & 0.048 & 2.387 & Up & $\begin{array}{l}\text { Tumor suppressive miRNA, which decreased breast cancer } \\
\text { cell migration and invasion }(31)\end{array}$ \\
\hline $\operatorname{miR}-106 b-3 p$ & 0.014 & 4.186 & Down & $\begin{array}{l}\text { Downregulated in bone metastasis patients with } \\
\text { breast cancer (17) }\end{array}$ \\
\hline $\operatorname{miR}-1237-3 p$ & 0.048 & 2.876 & Up & $\mathrm{N} / \mathrm{A}$ \\
\hline miR-136-5p & 0.044 & 7.102 & Down & $\mathrm{N} / \mathrm{A}$ \\
\hline $\operatorname{miR}-181 a-3 p$ & 0.028 & 7.355 & Down & $\mathrm{N} / \mathrm{A}$ \\
\hline miR-196a-5p & 0.044 & 2.222 & Down & $\mathrm{N} / \mathrm{A}$ \\
\hline $\operatorname{miR}-218-5 p$ & 0.019 & 7.687 & Down & Downregulated in cisplatin-resistant breast cancer cell lines (23) \\
\hline $\operatorname{miR}-342-5 p$ & 0.016 & 4.669 & Down & $\begin{array}{l}\text { Downregulation associates with early recurrence in patients } \\
\text { with breast cancer (32) }\end{array}$ \\
\hline $\operatorname{miR}-362-5 p$ & 0.026 & 3.357 & Down & $\mathrm{N} / \mathrm{A}$ \\
\hline $\operatorname{miR}-376 a-3 p$ & 0.027 & 3.941 & Down & $\mathrm{N} / \mathrm{A}$ \\
\hline $\operatorname{miR}-376 c-3 p$ & 0.018 & 5.352 & Down & N/A \\
\hline miR-505-5p & 0.017 & 4.369 & Down & $\begin{array}{l}\text { Tumor suppressive miRNA, which correlates inversely with } \\
\text { drug sensitivity }(25)\end{array}$ \\
\hline $\operatorname{miR}-550 a-5 p$ & 0.049 & 3.647 & Up & N/A \\
\hline $\operatorname{miR}-6515-3 p$ & 0.010 & 6.535 & Up & N/A \\
\hline
\end{tabular}

pCR, pathological complete response; N/A, not applicable.

knowledge, the involvement of the other 28 miRNAs identified in this study with breast cancer has not been previously reported.

In a study using pretreatment biopsy specimens, Kolacinska et al (37) reported correlations between miRNA expression profiles and the pathological response of neoadjuvant chemotherapy. This group investigated the expression profiles of 19 miRNAs in frozen biopsy specimens collected from patients with ER-negative, PR-negative and HER2-negative (triple-negative) breast cancer, and observed that miR-200b-3p, miR-190a and miR-512-5p were associated with a better pathological response. However, there were no differences in the expression levels of these three miRNAs between the non-pCR and pCR groups in our study. Most triple-negative breast cancers belong to different molecular subtypes of ER- and/or HER2-positive breast cancers (38), and miRNA expression of triple-negative breast cancers differed compared with other subtypes $(14,15)$. Triple-negative breast cancer tends to behave more aggressively than other subtypes; there are currently no therapies targeting the endocrine system or HER2 for this subtype of breast cancer. Taken together, it appears that there are differences in miRNA profiles associated with pathological response according to subtype.

miRNAs associated with the pathological response of neoadjuvant chemotherapies in patients with HER2-positive breast cancer have been reported in several studies using circulating miRNA. Circulating miRNAs may be exploited as noninvasive biomarkers since miRNAs derived from tumors are stable and detectable in serum $(39,40)$. For example, Jung et al (34) reported that the expression level of circulating miR-210 was associated with the sensitivity of neoadjuvant chemotherapy in patients with HER2-positive breast cancer, while Müller et al (35) reported that serum levels of miR-21, miR-210 and miR-373 were higher in patients with HER2-positive breast cancer than in healthy females, although no associations between circulating miRNAs with pCR were noted. The present study revealed that miR-210 upregulation was associated with non-pCR (Tables III and IV). Therefore, upregulation of miR-210 may be useful to predict the pathological response of neoadjuvant chemotherapy with trastuzumab, although these results cannot be validated due to the differences in analyses and chemotherapy regimens.

In this study, we determined miRNA profiles in FFPE sections of pretreatment biopsy specimens that were obtained prior to neoadjuvant chemotherapy. miRNA is stable and intact in FFPE, while mRNA is fragmented in FFPE tissue compared with fresh tissue (41). Our results also revealed degradation of RNA, and RNA fragments extracted from FFPE tissue were as short as 100 nt (Fig. 2). miRNAs appear to be better preserved, possibly due to their intrinsically shorter lengths (42). Microarray analysis of miRNA expression profiles demonstrated good correlations between frozen and FFPE samples (43). FFPE tissues are often the only available tissue samples in several institutions, and have usually been archived for long periods. This stability and availability in the clinical setting are advantages of miRNA study using FFPE. As another advantage of this study, an LMD system was used during the process of RNA extraction. The LMD system enables access to specific regions within tissue samples to collect relevant information (44). RNA was extracted from tumor tissue sections collected from biopsy specimens. Since the validity of microarray analysis of microdissected tumor 
tissues from FFPE samples has been reported (45), we consider that our approach was reasonable.

There are certain limitations to this study that should be addressed. First, the sample size was relatively small and this retrospective study was limited to a single institution. Second, there exists no consensus on a method to normalize miRNA microarray data (46). Data normalization is necessary to minimize the effects of systemic experimental bias and technical variations. Although our data were analyzed using 90th percentile normalization, other normalization methods may lead to different results. Third, our results have not yet been verified, and therefore we cannot discount the possibility that the results were random. The candidate miRNAs should be verified by quantitative polymerase chain reaction analysis, and the prediction models should ideally be verified against a validation cohort.

In conclusion, the results of our study demonstrated differential miRNA expression profiles between pCR and non-pCR groups, following neoadjuvant chemotherapy with trastuzumab in patients with HER2-positive breast cancer. The combination of miRNA profiles and ER status may improve the accuracy of prediction of pathological responses to enable the design of personalized treatment regimens. The results of this study may be verified in larger and multicenter studies as this study used FFPE samples, which are generally available in most institutions. The findings of this study may be helpful to identify new predictive biomarkers to monitor the response of neoadjuvant chemotherapies.

\section{Acknowledgements}

The authors thank Nobuko Nishiaki and Taeko Yatabe of the Department of Surgery, Jichi Medical University, for their valuable technical assistance with regard to the preparation of pathological specimens and handling of RNA samples, as well as Enago (www.enago.jp) for the English language review. This study was supported by the Practical Research for Innovative Cancer Control (grant no. 15ck0106045h0002) from the Japan Agency for Medical Research and Development, AMED.

\section{References}

1. Ross JS, Slodkowska EA, Symmans WF, Pusztai L, Ravdin PM and Hortobágyi GN: The HER-2 receptor and breast cancer: ten years of targeted anti-HER-2 therapy and personalized medicine. Oncologist 14: 320-368, 2009.

2. Slamon DJ, Clark GM, Wong SG, Levin WJ, Ullrich A and McGuire WL: Human breast cancer: correlation of relapse and survival with amplification of the HER-2/neu oncogene. Science 235: 177-182, 1987.

3. Slamon DJ, Leyland-Jones B, Shak S, Fuchs H, Paton V, Bajamonde A, Fleming T, Eiermann W, Wolter J, Pegram M, et al: Use of chemotherapy plus a monoclonal antibody against HER2 for metastatic breast cancer that overexpresses HER2. N Engl J Med 344: 783-792, 2001

4. Perez EA, Romond EH, Suman VJ, Jeong JH, Sledge G, Geyer CE Jr, Martino S, Rastogi P, Gralow J, Swain SM, et al: Trastuzumab plus adjuvant chemotherapy for human epidermal growth factor receptor 2-positive breast cancer: planned joint analysis of overall survival from NSABP B-31 and NCCTG N9831. J Clin Oncol 32: 3744-3752, 2014.

5. Rastogi P, Anderson SJ, Bear HD, Geyer CE, Kahlenberg MS, Robidoux A, Margolese RG, Hoehn JL, Vogel VG, Dakhil SR, et al: Preoperative chemotherapy: updates of national surgical adjuvant breast and bowel project protocols B-18 and B-27. J Clin Oncol 26: 778-785, 2008.
6. Kong X, Moran MS, Zhang N, Haffty B and Yang Q: Meta-analysis confirms achieving pathological complete response after neoadjuvant chemotherapy predicts favourable prognosis for breast cancer patients. Eur J Cancer 47: 2084-2090, 2011.

7. Buzdar AU: Significantly higher pathologic complete remission rate after neoadjuvant therapy with trastuzumab, paclitaxel, and epirubicin chemotherapy: results of a randomized trial in human epidermal growth factor receptor 2-positive operable breast cancer. J Clin Oncol 23: 3676-3685, 2005.

8. Gianni L, Eiermann W, Semiglazov V, Manikhas A, Lluch A, Tjulandin S, Zambetti M, Vazquez F, Byakhow M, Lichinitser M, et al: Neoadjuvant chemotherapy with trastuzumab followed by adjuvant trastuzumab versus neoadjuvant chemotherapy alone, in patients with HER2-positive locally advanced breast cancer (the NOAH trial): a randomised controlled superiority trial with a parallel HER2-negative cohort. Lancet 375: 377-384, 2010.

9. Goldhirsch A,WinerEP, Coates AS, GelberRD,Piccart-Gebhart M, Thürlimann B and Senn HJ; Panel members: Personalizing the treatment of women with early breast cancer: highlights of the St Gallen international expert consensus on the primary therapy of early breast cancer, 2013. Ann Oncol 24, 2206-2223, 2013.

10. Cortazar P,Zhang L,Untch M, Mehta K, Costantino JP, Wolmark N, Bonnefoi H, Cameron D, Gianni L, Valagussa P, et al: Pathological complete response and long-term clinical benefit in breast cancer: the CTNeoBC pooled analysis. Lancet 384: 164-172, 2014.

11. Mulrane L, McGee SF, Gallagher WM and O'Connor DP: miRNA dysregulation in breast cancer. Cancer Res 73: 6554-6562, 2013.

12. Wang SE and Lin RJ: MicroRNA and HER2-overexpressing cancer. Microrna 2: 137-147, 2013.

13. Serpico D, Molino L and Di Cosimo S: microRNAs in breast cancer development and treatment. Cancer Treat Rev 40: 595-604, 2014.

14. Blenkiron C, Goldstein LD, Thorne NP, Spiteri I, Chin SF, Dunning MJ, Barbosa-Morais NL, Teschendorff AE, Green AR, Ellis IO, et al: MicroRNA expression profiling of human breast cancer identifies new markers of tumor subtype. Genome Biol 8: $\mathrm{R} 214,2007$.

15. Dai X, Chen A and Bai Z: Integrative investigation on breast cancer in ER, PR and HER2-defined subgroups using mRNA and miRNA expression profiling. Sci Rep 4: 6566, 2014.

16. Wolff AC, Hammond MEH, Schwartz JN, Hagerty KL, Allred DC, Cote RJ, Dowsett M, Fitzgibbons PL, Hanna WM, Langer A, et al: American Society of Clinical Oncology/College of American Pathologists guideline recommendations for human epidermal growth factor receptor 2 testing in breast cancer. J Clin Oncol 25: 118-145, 2007.

17. Ni X, Xia T, Zhao Y, Zhou W, Wu N, Liu X, Ding Q, Zha X, Sha J and Wang S: Downregulation of miR-106b induced breast cancer cell invasion and motility in association with overexpression of matrix metalloproteinase 2. Cancer Sci 105: 18-25, 2014.

18. Isobe T, Hisamori S, Hogan DJ, Zabala M, Hendrickson DG, Dalerba P, Cai S, Scheeren F, Kuo AH, Sikandar SS, et al: miR-142 regulates the tumorigenicity of human breast cancer stem cells through the canonical WNT signaling pathway. Elife 3, 2014.

19. Huang S, Chen Y, Wu W, Ouyang N, Chen J, Li H, Liu X, Su F, Lin L and Yao Y: miR-150 promotes human breast cancer growth and malignant behavior by targeting the pro-apoptotic purinergic P2X7 receptor. PLoS One 8: e80707, 2013.

20. Lowery AJ, Miller N, Devaney A, McNeill RE, Davoren PA, Lemetre C, Benes V, Schmidt S, Blake J, Ball G and Kerin MJ: MicroRNA signatures predict oestrogen receptor, progesterone receptor and HER2/neu receptor status in breast cancer. Breast Cancer Res 11: R27, 2009.

21. Madhavan D, Zucknick M, Wallwiener M, Cuk K, Modugno C, Scharpff M, Schott S, Heil J, Turchinovich A, Yang R, et al: Circulating miRNAs as surrogate markers for circulating tumor cells and prognostic markers in metastatic breast cancer. Clin Cancer Res 18: 5972-5982, 2012.

22. Li M, Ma X, Li M, Zhang B, Huang J, Liu L and Wei Y: Prognostic role of microRNA-210 in various carcinomas: a systematic review and meta-analysis. Dis Markers 2014: 106197, 2014.

23. He X, Xiao X, Dong L, Wan N, Zhou Z, Deng H and Zhang X: MiR-218 regulates cisplatin chemosensitivity in breast cancer by targeting BRCA1. Tumour Biol 36: 2065-2075, 2015.

24. Lv J, Xia K, Xu P, Sun E, Ma J, Gao S, Zhou Q, Zhang M, Wang F, Chen F, et al: miRNA expression patterns in chemoresistant breast cancer tissues. Biomed Pharmacother 68: 935-942, 2014. 
25. Yamamoto Y, Yoshioka Y, Minoura K, Takahashi RU, Takeshita F, Taya T, Horii R, Fukuoka Y, Kato T, Kosaka N and Ochiya T: An integrative genomic analysis revealed the relevance of microRNA and gene expression for drug-resistance in human breast cancer cells. Mol Cancer 10: 135, 2011.

26. Shen J,Hu Q, Schrauder M, YanL, Wang D, MedicoL, Guo Y,YaoS, Zhu Q, Liu B, et al: Circulating miR-148b and miR-133a as biomarkers for breast cancer detection. Oncotarget 5: 5284-5294, 2014.

27. Pinto R, De Summa S, Danza K, Popescu O, Paradiso A, Micale L, Merla G, Palumbo O, Carella M and Tommasi S: MicroRNA expression profiling in male and female familial breast cancer. Br J Cancer 111: 2361-2368, 2014

28. Shi W, Gerster K, Alajez NM, Tsang J, Waldron L, Pintilie M, Hui AB, Sykes J, P'ng C, Miller N, et al: MicroRNA-301 mediates proliferation and invasion in human breast cancer. Cancer Res 71: 2926-2937, 2011.

29. Kim NH, Kim HS, Li XY, Lee I, Choi HS, Kang SE, Cha SY, Ryu JK, Yoon D, Fearon ER, et al: A p53/miRNA-34 axis regulates Snaill-dependent cancer cell epithelial-mesenchymal transition. J Cell Biol 195: 417-433, 2011.

30. Cuk K, Zucknick M, Heil J, Madhavan D, Schott S, Turchinovich A, Arlt D, Rath M, Sohn C, Benner A, et al: Circulating microRNAs in plasma as early detection markers for breast cancer. Int J Cancer 132: 1602-1612, 2013

31. Kim SJ, Shin JY, Lee KD, Bae YK, Sung KW, Nam SJ and Chun KH: MicroRNA let-7a suppresses breast cancer cell migration and invasion through downregulation of C-C chemokine receptor type 7. Breast Cancer Res 14: R14, 2012.

32. Pérez-Rivas LG, Jerez JM, Carmona R, de Luque V, Vicioso L, Claros MG, Viguera E, Pajares B, Sánchez A, Ribelles N, et al: A microRNA signature associated with early recurrence in breast cancer. PLoS One 9: e91884, 2014.

33. Perou CM, Sørlie T, Eisen MB, van de Rijn M, Jeffrey SS, Rees CA, Pollack JR, Ross DT, Johnsen H, Akslen LA, et al: Molecular portraits of human breast tumours. Nature 406: 747-752, 2000.

34. Jung EJ, Santarpia L, Kim J, Esteva FJ, Moretti E, Buzdar AU, Di Leo A, Le XF, Bast RC Jr, Park ST, et al: Plasma microRNA 210 levels correlate with sensitivity to trastuzumab and tumor presence in breast cancer patients. Cancer 118: 2603-2614, 2012.

35. Müller V, Gade S, Steinbach B, Loibl S, von Minckwitz G, Untch M, Schwedler K, Lübbe K, Schem C, Fasching PA, et al: Changes in serum levels of miR-21, miR-210 and miR-373 in HER2-positive breast cancer patients undergoing neoadjuvant therapy: a translational research project within the Geparquinto trial. Breast Cancer Res Treat 147: 61-68, 2014.

36. Camps C, Buffa FM, Colella S, Moore J, Sotiriou C, Sheldon H Harris AL, Gleadle JM and Ragoussis J: hsa-miR-210 is induced by hypoxia and is an independent prognostic factor in breast cancer. Clin Cancer Res 14: 1340-1348, 2008.
37. Kolacinska A, Morawiec J, Fendler W, Malachowska B, Morawiec Z, Szemraj J, Pawlowska Z, Chowdhury D, Choi YE, Kubiak R, et al: Association of microRNAs and pathologic response to preoperative chemotherapy in triple negative breast cancer: preliminary report. Mol Biol Rep 41: 2851-2857, 2014.

38. Sotiriou $\mathrm{C}$ and Pusztai L: Gene-expression signatures in breast cancer. N Engl J Med 360: 790-800, 2009.

39. Mitchell PS, Parkin RK, Kroh EM, Fritz BR, Wyman SK, Pogosova-Agadjanyan EL, Peterson A, Noteboom J, O'Briant KC, Allen A, et al: Circulating microRNAs as stable blood-based markers for cancer detection. Proc Natl Acad Sci USA 105: 10513-10518, 2008.

40. Chen X, Ba Y, Ma L, Cai X, Yin Y, Wang K, Guo J, Zhang Y, Chen J, Guo X, et al: Characterization of microRNAs in serum: a novel class of biomarkers for diagnosis of cancer and other diseases. Cell Res 18: 997-1006, 2008.

41. Pritchard CC, Cheng HH and Tewari M: MicroRNA profiling: approaches and considerations. Nat Rev Genet 13: 358-369, 2012.

42. Hui AB, Shi W, Boutros PC, Miller N, Pintilie M, Fyles T, McCready D, Wong D, Gerster K, Waldron L, et al: Robust global micro-RNA profiling with formalin-fixed paraffin-embedded breast cancer tissues. Lab Invest 89: 597-606, 2009.

43. Xi Y, Nakajima G, Gavin E, Morris CG, Kudo K, Hayashi K and Ju J: Systematic analysis of microRNA expression of RNA extracted from fresh frozen and formalin-fixed paraffin-embedded samples. RNA 13: 1668-1674, 2007.

44. Legres LG, Janin A, Masselon C and Bertheau P: Beyond laser microdissection technology: follow the yellow brick road for cancer research. Am J Cancer Res 4: 1-28, 2014.

45. Lassmann S, Kreutz C, Schoepflin A, Hopt U, Timmer J and Werner M: A novel approach for reliable microarray analysis of microdissected tumor cells from formalin-fixed and paraffin-embedded colorectal cancer resection specimens. J Mol Med (Berl) 87: 211-224, 2009.

46. Meyer SU, Pfaffl MW and Ulbrich SE: Normalization strategies for microRNA profiling experiments: a 'normal' way to a hidden layer of complexity? Biotechnol Lett 32: 1777-1788, 2010 . 